\title{
A BIBLIOMETRIC ANALYSIS OF THE RELATIONSHIP INTERNSHIP - SKILLS - EMPLOYABILITY
}

\begin{abstract}
Cristian Virgil MARINAȘ ${ }^{a *}$, Simona Irina GOIA ${ }^{b}$, Ana-Alexandra GORA ${ }^{c}$, Ramona Ștefania IGREṬ ${ }^{d}$, Monica ROMAN", Simona Cătălina ȘTEFAN ${ }^{f}$
\end{abstract}

${ }^{a, b, c, d, e, f}$ Bucharest University of Economic Studies, Romania

\begin{abstract}
This article aims at describing the interest of researchers in analysing students' skills, as an important factor for increasing employability, within the context of pursuing internships. Specifically, we aim at analysing by bibliometric methods the characteristics of the articles that are at the intersection of three essential underlying economic concepts - internships, competences/ skills/ abilities, employability - published in the last 10 years. The objective of the research is to outline: the dynamics of the number of studies, during a decade, in the time period 2010-2020; territorial distribution of these studies; distribution of the studies according to the research area; the relevance of the studies, as assessed by the number of citations and the links between the keywords mentioned in these studies. Thus, the present article contributes to the scientific literature in the field of management by analysing the association between skills, internship and employability in an indirect manner: using bibliometric analysis. There is a significant increase in the number of documents published after 2017, a distribution focused on geographical areas and fields of study, as well as an exponential increase in the number of citations, which emphasizes the high relevance of the topic analysed.
\end{abstract}

KEYWORDS : employability, internship, skills, bibliometric analysis

\section{INTRODUCTION}

As early as the 1990s, the success in the career of graduates started to be used as a key factor in assessing the quality of education in general and of higher education in particular (Chebeň, Lančarič, Munk \& Obdržálek, 2020). Thus, one important aspect of the quality of higher education is represented by the quality of the results obtained by graduates, which indicates that academic education brings added value by developing work-related skills and competences. Moreover, higher education institutions are obliged to provide continuous educational services, in form of postgraduate education, distance learning, lifelong learning of older or international students, and vocational/ professional education for different organizations, since there is an increased dependence between the public funding of the institution and the quality of the educational process. On the other hand, students ' perceptions of the quality of teaching are significantly affected by the source of educational funds, and the quality of education has an impact on graduates' career success and employability (Chebeň, Lančarič, Munk \& Obdržálek, 2020).

Employability has become a key issue in many countries, particular attention being paid to the role played by higher education in developing and fostering employability. As such, employability represents an attribute that facilitates success both in employment and in life; therefore, employability skills are also called "life skills" (Blackmore, 2015). Such skills can be successfully

\footnotetext{
* Corresponding author. E-mail address: cristian.marinas@man.ase.ro
} 
developed through partnerships with economic agents or through internship programmes. Skills that increase the employability of business administration students can also be improved through partnerships with local businesses (Spence \& Hyams-Ssekasi, 2015). The results of various studies reveal that these collaborations between universities and the business environment have positive results. However, despite the increasing popularity of internship programmes, surprisingly, little research investigating their effectiveness or their effects has been conducted so far.

This article aims at outlining the research interest for the analysis of students' skills, as a factor for increasing students' employability, in the context of pursuing internships. Specifically, our goal is to analyze by means of bibliometric methods the features of the studies that are at the intersection of the three essential underlying economic concepts - internships, competences/ skills/ abilities, employability - published in the last 10 years. The aim of the research is to analyse:

- The dynamics of the number of studies, during a decade, between 2010-2020;

- Territorial distribution and distribution according to the field of study of the documents;

- The relevance of the studies, as resulting from the number of citations;

- The links between the keywords mentioned in the studied documents.

Thus, the present article contributes to the scientific literature in the field of management by analyzing the association between students' skills, internships and employability in an indirect manner. Using the bibliometric analysis, an original contribution is made to the study of the interaction between the three above mentioned concepts, as resulting from the scientific literature of the last decade. As highlighted in the following sections, the relationship between internships, students' skills and their employability received increasing attention in the international research community in the last period of time, which confirms the relevance of the topic.

\section{EVIDENCE FROM THE SCIENTIFIC LITERATURE}

The existing scientific literature reveals a causal link between the three analysed concepts, which therefore fully justifies the purpose of this article. In order to analyse the connection between competencies, internships and employability, it is important to mention that competencies are analysed mainly from two perspectives: the taxonomy and their assessment method.

Hilton (2015) addresses the skills of the future, needed in the professional field, society and family, referring mainly to the situation in the United States; however, the outcome could easily be extrapolated to other countries, including Romania. Both employers and third-party actors involved in the development of educational policies frequently refer to 21 st century skills, mentioning skills such as teamwork, problem-solving, self-management, skills that should be developed and trained in school and later on in universities.

Lavi et al. (2021) aim at establishing a link between different categories of skills of the 21 st century and different teaching and learning methods, both active and passive. The authors identify 14 competencies for science, technology, engineering, and mathematics (STEM) university graduates, which following the factor analysis are grouped into three broad categories of the 21 st century competencies: (1) general competencies (complex problem solving, critical thinking, individual learning, questioning), (2) soft skills (creativity, collaboration, intercultural communication, entrepreneurship, oral communication, written communication) and (3) skills specific to the STEM field (engineering design, experimentation and testing, application of STEM knowledge, systemic thinking). Hwang and Kwon (2019) also explore the topic of competencies at the university level. The competency measurement tool is based on eight key competency areas that have been developed involving all stakeholders: personality skills, communication skills, complex thinking, information research, creativity, information use, global skills, leadership. The results of the study are used to identify the needs not covered by the curriculum and to formulate recommendations for its improvement. 
Slof et al. (2016) research the interpersonal skills and the group members perception on them in order to predict individual and group performance in environments where computer-assisted collaborative learning (CSCL) is practiced. Interpersonal skills refer to the ability of conflict resolution, the decision making ability, leadership skills, the ability to discuss and conduct a dialogue, the ability to empathize and team building. Employment opportunities in the labour market are significantly influenced by the knowledge, skills and competences owned by the job candidates. Dania, Bakar and Mohamed (2014) consider that in the global economy, workers need as much technical knowledge and skills as possible - these are often specific to the workplace and are not transferable - but in addition to these skills, if they want to contribute to the growth of an industry or corporation, they should also possess a wide range of soft skills, such as the employment skills. According to Barnett (2006), employment skills enable people to get a suitable job, and at the same time to develop their careers in the context of continuous social and technological change. Considering the social and technological dynamics, the competency-based employability perspective is highly important because it focuses on those employment skills that students or graduates should have in order to increase their chances of finding a job.

Nicolescu and Nicolescu (2018) conducted a study among the students from the Bucharest University of Economic Studies which researched the links between various employment skills (professional skills, transferable individual skills, transferable social skills, personal skills, the ability to search for jobs and corporate skills related to work) and the confidence of students/graduates in their own employability (the level of certainty that students/ graduates have about their own employability, namely the ability to obtain and keep a job). The results of this study reveal that there are four categories of skills that positively and significantly influence the confidence of students/graduates in their own employability, namely: personal skills, professional skills, the ability to search for jobs and transferable social skills, while transferable individual skills and work-related corporate skills do not have a significant influence on confidence in employability. Fenta et al. (2019) believe that the employability of university graduates is influenced to a large extent by the skills and education received, but also by many other factors related to the economic context. Factors that ensure success on the labour market can be approached from two perspectives: field specific skills and soft-skills.

Gora, Ștefan, Popa and Albu (2019) conducted a study among 496 students from two public universities in Romania and identified a number of factors related to quality management in higher education that could influence the skills acquired or employment opportunities of students. These factors are: the quality of the educational process (quality of educational content, quality of teachers and quality of teaching activities), infrastructure and equipment of the university, practical activities involving students and scientific research activities. The results of this study highlight that the educational process, represented by the quality of educational content, the quality of teachers and the quality of teaching activities, directly and positively influences the chances of employment on the labour market. This means that it is necessary for universities to design the content of the disciplines in order to adapt to the needs on the labour market.

Narayanan, Olk and Fukami (2010) identify the different roles of the three main actors involved in the internship programmes - students, universities and companies and reveal the importance of the behaviour of each actor involved in the process and the actual importance of a proper management of the internship programme in explaining students' satisfaction. Nghia and Duyen (2018) analyse the learning outcomes of internships and the factors which lead to these results. The aim of their paper is to explore the experiences of trainees in the field of tourism and hospitality in Vietnam in order to identify the dimensions of the learning outcomes of the internship programmes and the factors that influence these learning outcomes. There is evidence that the internships helped students to consolidate the existing knowledge and skills, to further develop relevant professional skills, to shape their career paths and to adjust and adapt their learning attitudes and behaviours. 
Popescu and Mocanu (2018) investigate the effect of apprenticeship on the employability of young people in Romania. The paper provides details about young people's experience with apprenticeships in the Romanian context. There is empirical evidence which supports the hypothesis that work-based learning programs could increase the employability of young people. In a similar manner, Anjum (2020) analyses the impact of internship programs on the professional and personal development of students in the field economics and business. The results of the study confirm the impact of internship programs on the development of the professional and personal skills of business students in Pakistan. Based on the research outcome briefly presented above, it can be concluded that the employment opportunities of students/ graduates on the labour market depend to a large extent on the knowledge acquired and skills owned. A crucial role in the development of these skills is played by the higher education institutions. It can also be pointed out that the successful transition from education to work, or a high employability rate after graduation, is influenced by a complex mix of factors, which include, but are not limited to: field-specific knowledge, general academic performance, soft skills, involvement in internship programmes during the academic studies, work experience of graduates, institutional reputation, specific factors related to quality management in higher education, etc.

\section{THEORETICAL AND METHODOLOGICAL FRAMEWORK}

\subsection{Theoretical model of the research}

The scientific literature highlights the crucial role played by internships in the process of increasing students' employability (Narayanan, Olk \& Fukami, 2010). Moreover, this relationship is moderated by the development of professional hard and soft skills. The students' internship programs have both an academic and a business component, generated by the actors involved in their development and implementation. Thus, the academic component is granted by the involvement of the university in the process of organizing the internship, by ensuring mentoring activities and validating the new practical knowledge acquired in accordance with the academic curriculum. In the same time, the economic agents have also a crucial contribution to the practical education of students, by creating a coherent framework in order to familiarize students with the job responsibilities and tasks. These two dimensions of the internship will develop students' professional skills. The impact of the internship is exerted both on the technical skills (hard) specific to each job, and on the soft skills, much more diverse, as already mentioned above. The development of these skills, as well as the acquisition of new skills have a positive effect on increasing the employability of students/ graduates. The causal model, which integrates the three main underlying concepts was developed by the authors of the present article and it is presented in the figure 1.

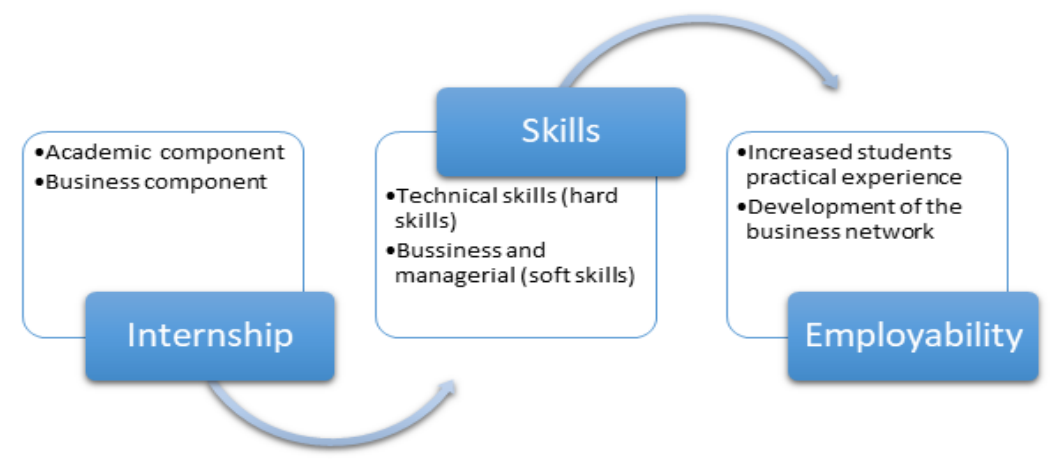

Figure 1. The theoretical model of the relationship: internship- skills- employability

Source: Authors' concept and illustration 
It is worth mentioning that most of the studies presented in the previous sections focus on the bilateral connection between these concepts: most documents analyze the effect of internships on employability or the effect of skills on employability. Therefore, the use of the three concepts in the same research design is still limited, but rapidly expanding.

\subsection{Defining the underlying concepts}

A skill is the learned ability to perform an action targeting certain results, with a good execution, often in a certain time frame and making use of specific resources. One of the first documents that define professional competencies is the SCANS Report (US Department of Labor, 1991), which identified work-related skills (called "Workplace Skills"). These refer to: the employee's ability to identify, organize, plan and allocate resources; the ability to work with others; and the ability to acquire and use information. In addition, personal qualities such as responsibility, self-esteem, sociability, self-management and a sense of integrity and honesty were also identified as necessary for the success of future employment. McLaughlin's (1995) study confirms the fundamental results provided in the SCANS Report. Employability is a complex concept that is the subject of several definitions and approaches. Thus, the definitions of employability focus on the transition of graduates to the labour market upon completion of higher education and can be classified into two main categories: those that are focused on employment (in terms of labour market demand) and those that are focused on skills (from the perspective of the supply of the education system). Thus, the first approach refers to the ability of graduates to find a job and have a professional activity that would meet the requirements of the employer. The second approach perceives employability as the set of personal skills and knowledge of graduates, which increases their chances of finding a job and having favourable results in their career choice (Commission Européenne, 2014).

On the other hand, although employability is rarely explicitly and clearly defined, there are several implicit definitions in the literature. Harvey (2001) considers that in all cases, the basic concept of individual employability refers to the capacity of students to get a job, distinguishing between individual and institutional employability which refers to institutional performance.

According to Yorke (2006), the individual employability represents a set of achievements, skills and personal attributes that make graduates obtain more easily a job and succeed in their chosen career. They have a personal benefit out of this situation, but also the labour force, the community and the economy benefits from this situation. Moreover, Yorke (2006) emphasizes that employability is a dynamic, constantly evolving concept that is linked to students' ability to learn from various experiences and situations.

Pardo-Garcia and Barac (2020) identify different ways in which higher education institutions could improve the employability of their students, namely:

- curriculum improvements (inviting potential employers from the business environment to universities, using ICT, using tutorials to help students adapt to university requirements, offering diplomas with double specializations, etc.);

- teaching business protocols (training the personal skills of students, such as decision making or problem solving, training the interpersonal skills such as teamwork or communication, training the entrepreneurial skills, etc.);

- matching jobs requirements (presenting job search forums, providing practical work experience, internships, etc.);

- learning from the experience of alumni graduates (various activities with graduates, visits in companies where graduates work, etc.).

There are a wide variety of faculty-mediated programs that aim to develop students' professional skills. McLaughlin (1995) mentions mentoring, apprenticeship programs (more specific to dual education) and internships. The author defines a typical internship program by four components: (1) a certain number of hours, (2) a paid or unpaid work component, (3) school/ academic credits, and (4) supervision provided by a faculty coordinator and a corporate counterpart. 


\subsection{Materials and methods}

This article aims at emphasizing the interest of researchers, at this moment in time, for the analysis of skills as a factor of increasing employability, in the context of pursuing internship programs. In order to analyse the existing links between the concepts of skills, internships and employability, bibliometric analysis was deployed. Bibliometric methods are used to provide quantitative analyses of written publications, based on the identification of the corpus of literature, respectively of publications in their broadest sense, in a given field (Ellegaard and Wallin, 2015).

In accordance with the declared scope of the present article, in June 2021, a keyword search process was conducted in the Core Collection Web of Science (WoS) database. Thus, the search was performed in the "topic" section of the WoS database (includes searches in the following fields within a record: title, abstract, author keywords and Keywords plus), by the keywords "competence *" or "skill *", "internship *" and "employability *". After each keyword, the symbol * was added in order to find all possible combinations of keywords (e.g. competence and competences, or internship or internships). Initially, the search was carried out taking into account the aforementioned criteria for the last two decades, namely the time period 2000-2020. However, given that only 3 items belonging to the period 2000-2009 were identified, in a second iteration the search period was restricted to the time period 2010-2020. The distribution of the items over the years 2010-2020 indicates that the research about the common topic - skills, internships, employability - intensified significantly in the last decade. Thus, the time period 2010-2020 is considered relevant for the present bibliometric study. Moreover, to perform the keyword analysis and create the visualization map of keywords, a database with information specific to the 163 documents was created. Specifically, various information on the selected documents was extracted from the Web of Science platform, more precisely information on the title of the document, the names of the authors, the year of publication, the abstract and the keywords of each document. Following the creation of this database, to analyze the links between the keywords mentioned in the 163 documents, the VOSviewer software (van Eck \& Waltman, 2021) developed by Nees Jan van Eck and Ludo Waltman (van Eck \& Waltman, 2011) was used. VOSviewer is a computer program that can be used for creating, visualizing and exploring bibliometric maps of science (van Eck \& Waltman, 2010). In order to build a visualization maps of keywords, the software VOSviewer uses the VOS (visualization of similarities) mapping technique (van Eck \& Waltman, 2007).

\section{RESULTS AND DISCUSSIONS}

\subsection{The analysis of the documents published on the topic internship - skills - employability in the time period $2010-2020$}

Taking into account the criteria mentioned above, the search was carried out in the database Web of Science (WoS) Core Collection. The result consists in 163 documents published between 20102020 (11 years) that will be analysed in this study. As presented in Table 1, approximately $85 \%$ of the documents were published between 2015 and 2020, which indicates that scientific interest in this field has increased significantly in recent years. In the first years under analysis, namely 2010 and 2011, no documents were identified; starting with 2012 their number will increase, from 2 in 2012 to 33 in 2017. Subsequently, a slight regression took place (29 items were identified in 2018), followed by an increase to 39 in 2019 and then again a regression. In 2020, only 24 studies were identified, but it is possible that their actual number will be higher, since for some volumes from 2020 the process of indexing is probably still in progress. The fact that in the last 4 years the number of documents addressing the 3 key concepts has increased considerably suggests the growing interest of the scientific community for the analysis of internships as trigger and accelerator of better skills and employability. 
Table 1. Evolution of the items' frequency in the time period $2010-2020$

\begin{tabular}{|c|c|c|c|}
\hline Year & Frequency & Percentage & Cumulated percentage \\
\hline 2010 & 0 & $0,00 \%$ & $0,00 \%$ \\
\hline 2011 & 0 & $0,00 \%$ & $0,00 \%$ \\
\hline 2012 & 2 & $1,23 \%$ & $1,23 \%$ \\
\hline 2013 & 3 & $1,84 \%$ & $3,07 \%$ \\
\hline 2014 & 6 & $3,68 \%$ & $6,75 \%$ \\
\hline 2015 & 14 & $8,59 \%$ & $15,34 \%$ \\
\hline 2016 & 13 & $7,98 \%$ & $23,31 \%$ \\
\hline 2017 & 33 & $20,25 \%$ & $43,56 \%$ \\
\hline 2018 & 29 & $17,79 \%$ & $61,35 \%$ \\
\hline 2019 & 39 & $23,93 \%$ & $85,28 \%$ \\
\hline 2020 & 24 & $14,72 \%$ & $100,00 \%$ \\
\hline Total & & $\mathbf{1 6 3}$ items \\
\hline
\end{tabular}

Source: Authors' illustration based on WoS

Regarding the distribution of documents according to the country to which the authors are affiliated, the authors of the 163 documents published in the time period 2010-2020 on the topic skill internship - employability were affiliated to 43 countries. The distribution by country is quite polarized. Australian authors exhibit the greatest interest in this field of research: almost $13 \%$ of the total production in the field present in WoS belongs to them, followed by the researchers from Spain (11.66\%), United States of America (10.43\%), England (9.82\%) and Portugal (8.59\%). Thus, it can be observed that the top 5 countries, namely Australia, Spain, The United States of America, England and Portugal produce over $50 \%$ of the total number of documents in the field. Therefore, there is a particular interest in this issue in these countries and the factors that determine this could be analyzed in a further study. It is worth mentioning that Romania ranks 8 th, with a number of 8 documents, which represents almost $5 \%$ of the total scientific production existing in WoS at the time of the search. The authors with the most representative contributions related to the analysed topic are from the the USA. Jackson has 4 contributions, followed by a number of 5 authors (Carter L, Escudeiro N, Mardis Ma, Mcclure Cr, Spears Li), each of them author of 3 documents in the field. They are followed by 16 authors with 2 contributions each. The authors of the 163 documents are affiliated to 213 organizations, most of them universities. The universities where the most studies in the field were elaborated are Macquarie University in Australia and Universidade de Aveiro in Portugal (4 documents each). The universities with the largest number of documents in the field come, as it could be easily intuited, mainly from the countries of origin of the authors with the largest number of studies. It should be mentioned that in the ranking of the first 29 universities we can find the Bucharest University Economic Studies (Romania), which generated 2 articles in WoS during 2010-2020 on the topic skills - internships - employability. Regarding the journals or volumes of the conferences in which the 163 analysed papers were published, 135 sources in which they were published were identified. Most documents are grouped around several conferences and journals in the field of education. About $20 \%$ of the documents can be found in the volumes of the different editions of the INTED Conference (International Education Conference), about 8.5\% within ICERI (International Conference of Education, Research and Innovation) and about 8.5\% within EDULEARN (International Conference on Education and New Learning Technologies). The 
journals with a significant number of studies on the analysed topic are also in the field of education: Education and Training (6.14\%) and Higher Education Skills and Work Based Learning (4.91\%).

Over $60 \%$ of the selected documents are published in journals/ volumes of conferences in the category Education/ Educational Research. At a considerable distance, with a percentage of less than $10 \%$ of the total number of documents there are areas such as Education / Scientific Disciplines (8.59\%), Management (6.14\%), Interdisciplinary Social Sciences (5.52\%), Business (3.68\%) and Multidisciplinary Engineering (3.68\%).

\subsection{Analysis of citations}

The evolution of the citations cumulated by the 163 analysed papers in the time period 2010-2020 is illustrated in Figure 2. The evolution of citations has a similar trajectory to the number of documents: starting with 2017 it can be observed an exponential increase, which indicates the growing interest of the scientific community for this topic in the last five years. The direct correlation between the number of documents in the field and citations is natural and logical, as it can be assumed that the newly published studies also cite existing documents from the research field. This means that an increase in scientific output leads implicitly to an increase in the number of citations on this topic.

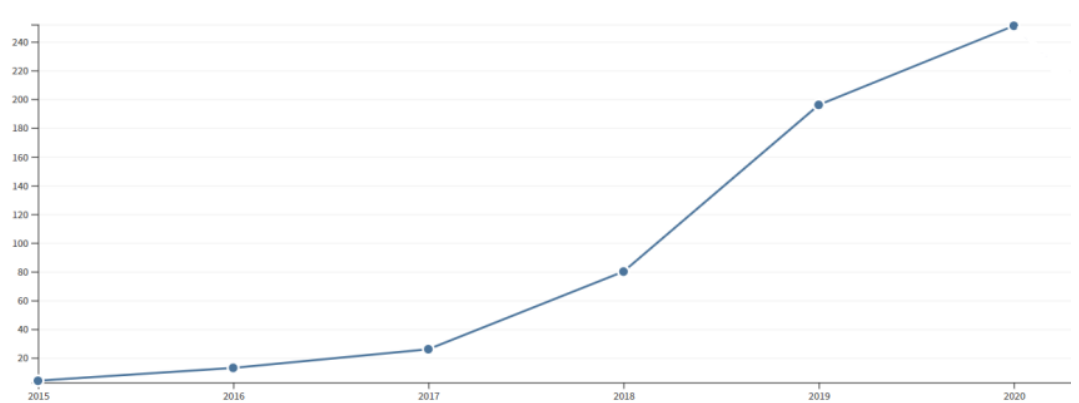

Figure 2. Evolution of citations in the time period 2010-2020

Source: Authors' illustration based on WoS

In the time period 2010-2020, the 163 documents under analysis accumulated a number of 570 citations. The most cited article (84 citations during 2010-2020) is Clarke's article (2018) which approaches the employability of graduates. On the second place, with 28 citations, can be found the article of Jacobone and Moro (2015) which alyses the role of ERASMUS programs on European competences and identity. On the third place, with 27 citations, is an article of Chillas, Marks and Galloway (2015) on the evaluation of internship programs and employability in the sector of information and communication technologies (ICT sector). Topics of interest, intensely quoted, include: how the curriculum develops students' employability skills, women's career development and equality of chances, assessing the impact of career management skills and internship programs within a business university, employers' perception of graduates' employment skills, improving the curriculum in order to increase employability, assessing employers' perceptions of internships, etc.

\subsection{Analysis of keywords}

In addition to the analysis of the published documents and the evolution of the citations received by the 163 studies, this article aimed to analyze the links between the keywords mentioned in the documents published on the topic "internship - skills - employability". Thus, the VOSviewer software (van Eck \& Waltman, 2021) developed by Nees Jan van Eck and Ludo Waltman (van Eck \& Waltman, 2011) was used to perform this analysis. After entering the data in the VOSviewer software, it counted a total of 664 keywords mentioned in the 163 documents analyzed. To analyze the links between the most frequently mentioned keywords, those keywords that appeared together 
in at least 5 of the 163 documents were kept for analysis, and more precisely 31 keywords met this criterion. For a more detailed analysis of the 31 keywords, as well as the links between them, the map of the keywords and their grouping in clusters was made, using the VOS clustering technique, a technique described in detail by the authors Waltman, van Eck and Noyons (2010). The VOS clustering technique uses, as explained by other authors (Cicea et al., 2019; Marinescu et al. 2019, Popa \& Gora, 2020), the number of nodes (by a node is meant a keyword represented on the map) and the links between them, as well as the total number of links and the total strength of between them (the number of co-occurrence). More specifically, based on the elements used, the VOS clustering technique calculates for each node its distance from other nodes and positions each node in a two-dimensional space (a representation called mapping) and creates the cluster to which the node belongs to. In this regard, the map of the 31 selected keywords according to a minimum of 5 occurrences in the 163 documents is illustrated in Figure 3.

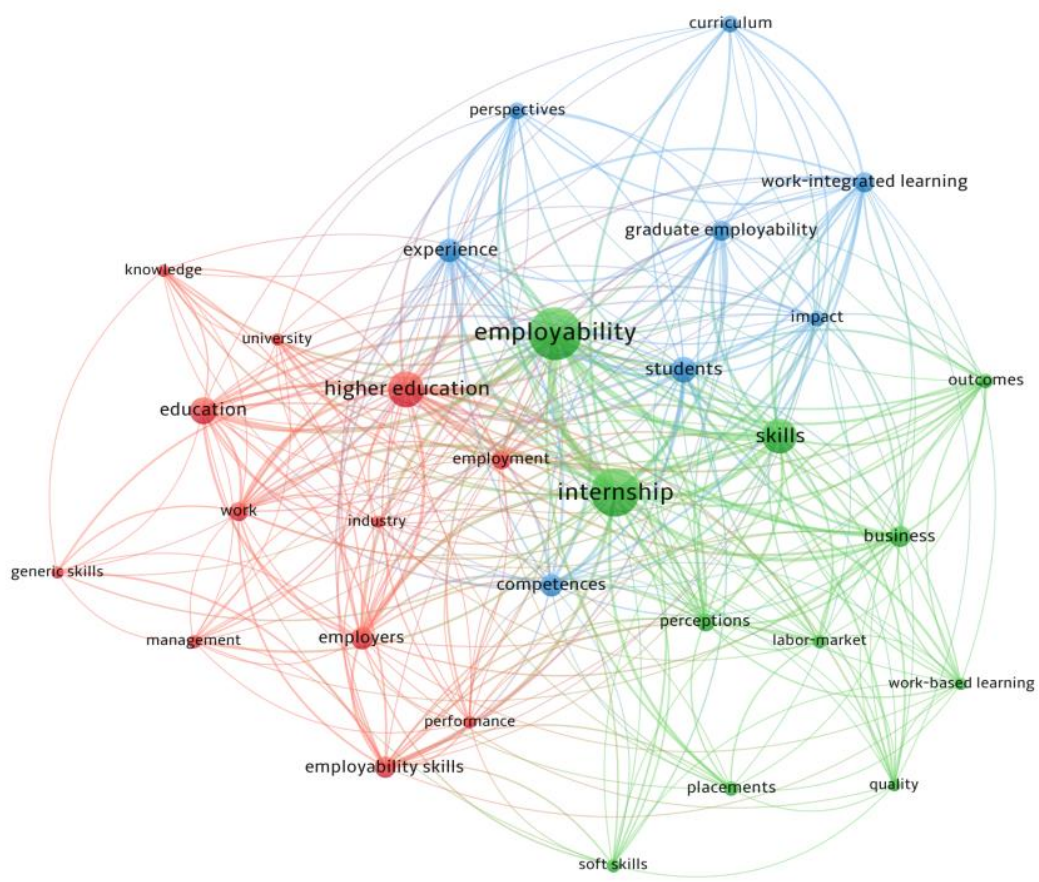

B vosviewer

Figure 3. Keyword map

Source: Authors with VOSviewer

Based on the information highlighted in Figure 3, it can be observed that the 31 keywords, represented in the keyword map by a node, are grouped into three clusters, depending on the links that form between them when they are mentioned together in the list of keywords of selected documents. The first cluster, the red one, includes 12 nodes or more precisely 12 keywords that were used together in the documents published on the topic "internship - skills - employability", namely: "education", "employability skills", "employers", "employment", "generic skills", "higher education", "industry", "knowledge", "management", "performance", "university" and "work". Analyzing the keywords grouped in this cluster, it can be highlighted that the documents published on the topics "internship - skills - employability" are closely related to the concept of education, and especially to higher education, as well as some concepts that refer at skills, knowledge and performance. This could highlight the important role of higher education institutions in organizing the educational process to match the students'skills with those required in the labor market. Depending on the size of the nodes, given by the number of documents in which a word appears as 
a keyword, it can be seen that from the red cluster, the word "higher education" is mentioned most frequently in the keyword list of selected documents. The second cluster is represented on the map in green. Depending on the links established between various keywords, mentioned in the keyword list of documents published on the topics "internship - skills - employability", within this cluster there are 11 nodes that refer to the following keywords: "business", "employability", "internship", "labor-market", "outcomes", "perceptions", "placements", "quality", "soft-skills" and "work-based learning". Furthermore, depending on the size of the nodes, the keywords 'employability' and 'internship' are the most frequently mentioned in the keyword list. The third cluster, highlighted in blue, comprises 8 nodes, namely: "competences", "curriculum", "experience", "graduate employability", "impact", "perspectives", "students" and "work-integrated". learning ". Within this cluster, the most common keywords in the keyword list of documents published on the topic "internship - skills - employability" are "students" and "experience", which could highlight the fact that skills development and participation in internships to increase the chances of employability could be specific to the student experience. Moreover, in addition to analyzing the keywords according to the links that are established between them, we consider it relevant to identify how the links between the keywords mentioned in the documents published on the topic "internship - skills employability" have evolved over time. In this sense, Figure 4 highlights the evolution over time of the links between different keywords relevant to the analyzed subject.

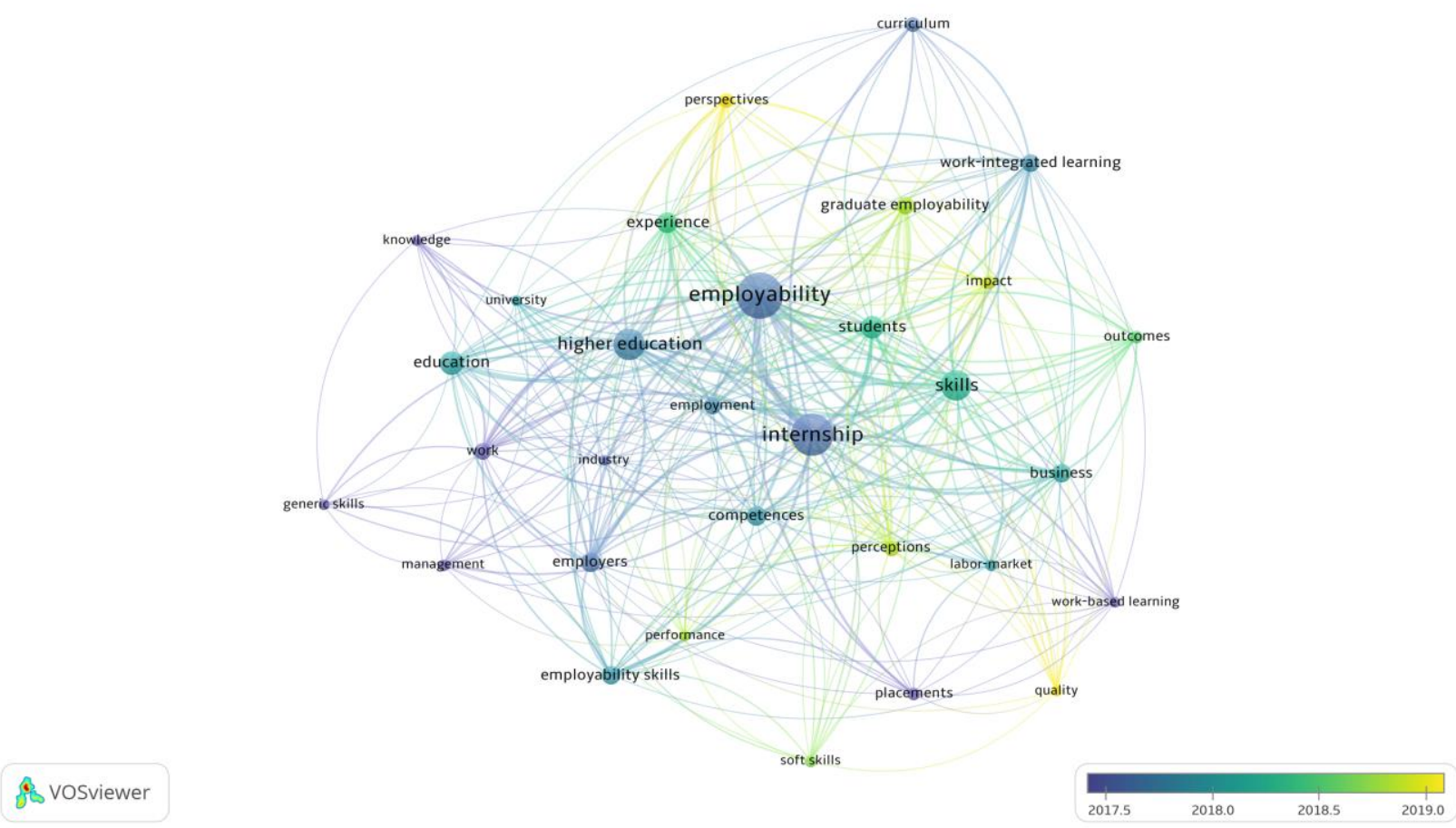

Figure 4. The evolution of the links between the keywords over time Source: Authors with VOSviewer

Figure 4 shows that in the period 2010-2017 the documents published on the topic "internship skills - employability" were closely related to some concepts such as "employability", "internship", "higher education", "work", "management". Subsequently, in the period 2017-2018, the documents published on the analyzed subject emphasize the fact that the interest of researchers has moved to a series of concepts such as "skills", "education", "students", "experience". More recently, documents published on the subject "internship - skills - employability" highlight that researchers have begun to focus on notions such as "graduate employability", "performance", "soft skills", "perspectives", "quality", "perceptions" and "impact". The recent use of the keywords "perceptions" and "impact" in the context of the analyzed topic could suggest proof of researchers' interest in highlighting the 
relationships between the concepts of internship, skills and employability and in terms of quantitative research.

\section{CONCLUSIONS}

The bibliometric analysis of the documents indexed in Web of Science, Core Collection that address in an integrated way the three sub-themes, skills-internships-employability, reveals a significant increase in the number of documents published after 2017. This trend indicates the growing interest of the scientific community for this topic in the last five years. The increased interest is also reflected in the evolution of citations, which also experienced a significant growth after 2017. Regarding the countries of origin of the most prolific authors in the field, 5 countries clearly take the lead, namely: Australia, Spain, The United States of America, England and Portugal, where more than $50 \%$ of the documents in the field are produced. Naturally, the universities to which the leading authors in the field are affiliated are located also mainly in the 5 countries that lead the top. It is noteworthy that there is a growing interest in the field also in our country, Romania being ranked $8^{\text {th }}$ in the top countries with the largest scientific contributions to this topic, and the Bucharest University of Economic Studies ranks $11^{\text {th }}$ in the top of organizations with the most representative contributions to the analysed topic. Over $35 \%$ of the 163 documents that resulted in WoS were published in the volumes of prestigious conferences in the field of education such as INTED (International Education Conference), ICERI (International Conference of Education, Research and Innovation) and EDULEARN (International Conference on Education and New Learning Technologies). Most journals with a significant number of articles on the analysed topic are also in the field of education or at the intersection of the fields of education (higher education) and management / business. The analysis of the keywords highlights the fact that the words "employability" and "internship" are mentioned in the keyword list of the most published documents on the topic "internship - skills - employability". Moreover, the 31 keywords mentioned in documents published on the analyzed topic are grouped into three clusters, creating various links between these concepts. In conclusion, the scientific community attaches increasing importance to the three concepts skills-internships-employability and to the links between them, as reflected in the significant number of documents published and their citations in WoS in recent years. The acquirement of the skills needed for employment is often influenced by pursuing internships in various organizations. The role of these internships and their quality are analysed by researchers and the main correlations are discussed. The results of the bibliometric analysis indicate the growing interest that the academic community has for the combined analysis of internships, skills and employability. The bibliometric data of the published papers is analysed, but their content, research methods employed or results are not approached at all. From this perspective, extending the research by taking also these elements into consideration could represent a direction for future research.

\section{ACKNOWLEDGEMENT}

The paper was supported by the Project "Practică inteligent dezvoltarea ta (Practice smart your development)" - PRIDE-U, POCU/626/6/13/133138.

\section{REFERENCES}

Anjum, S. (2020). Impact of internship programs on professional and personal development of business students: a case study from Pakistan. Future Business Journal, 6(1), 1-13.

Blackmore, P., Bulaitis, Z. H., Jackman, A. H., \& Tan, E. (2015). Employability in higher education: A review of practice and strategies around the world. London: Pearson. 
Barnett, R. (2006). Graduate attributes in an age of uncertainty. In P. Hager, \& S. Holland (Eds.). Graduate Attributes, Learning and Employability, 6: 49-65. DOI: 10.1007/1-4020-5342-8_3.

Chebeň, J., Lančarič, D., Munk, M., \& Obdržálek, P. (2020). Determinants of Economic Sustainability in Higher Education Institutions. Amfiteatru Economic, 22(54): 462 - 479. DOI: $10.24818 / \mathrm{EA} / 2020 / 54 / 462$.

Chillas, S., Marks, A., \& Galloway, L. (2015). Learning to labour: an evaluation of internships and employability in the ICT sector, New Technology Work And Employment, 30(1), 1-15. DOI: 10.1111/ntwe.12041.

Cicea, C., Marinescu, C., Albu, C. F., \& Bălan, D. P. (2019). Applying Bibliometric Mapping and Clustering on Research Regarding Biomass related Innovation, in Proceedings of the 33rd International Business Information Management Association Conference (IBIMA), 2404-2419.

Clarke, M. (2018). Rethinking graduate employability: the role of capital, individual attributes and context, Studies In Higher Education, 43(11), 1923-1937. DOI: 10.1080/03075079.2017.1294152.

Commission Européenne (2014). La modernisation de l'enseignement superieur en Europe: acces, retention et employabilite. Luxembourg, disponibil la https://op.europa.eu/en/publicationdetail/-/publication/59560dcc-a3c3-11e5-b528-01aa75ed71a1/language-fr/format-PDF, accesat în data de 23.05.2021.

Dania, J., Bakar, A. R., \& Mohamed, S. (2014). Factors Influencing the Acquisition of Employability Skills by Students of Selected Technical Secondary School in Malaysia. International Education Studies, 7(2), 117 - 124. DOI: 10.5539/ies.v7n2p117.

Ellegaard, O., \& Wallin, J. A. (2015). The bibliometric analysis of scholarly production: How great is the impact?. Scientometrics, 105, 1809-1831. DOI:10.1007/s11192-015-1645-z.

Fenta, H., Asnakew, Z. S., Debele, P. K., Nigatu, S. T., \& Muhaba, A. M. (2019). Analysis of supply side factors influencing employability of new graduates: A tracer study of Bahir Dar University graduates. Journal of Teaching and Learning for Graduate Employability, 10(2), 67-85.

Gora, A. A., Ștefan, S. C., Popa, Ș. C., \& Albu, C. F. (2019). Students' Perspective on Quality Assurance in Higher Education in the Context of Sustainability: A PLS-SEM Approach. Sustainability, 11(17), 4793. DOI:10.3390/su11174793.

Harvey, L. (2001). Defining and Measuring Employability. Quality in Higher Education, 7 (2), 97-109.

Hilton, M. (2015). Preparing Students for Life and Work, Issues in Science and Technology, 31(4), 63-66.

Hwang, S. W., \& Kwon, Y. A. (2019). An Exploration of Curriculum Development Directions Through an Analysis of University Students' Awareness of Core Competence, Asia-Pacific Education Researcher, 28, 213-227._DOI:10.1007/s40299-018-00429-x.

Jacobone, V., \& Moro, G. (2015). Evaluating the impact of the Erasmus programme: skills and European identity, Assessment \& Evaluation In Higher Education, 40(2), 309-328. DOI: 10.1080/02602938.2014.909005.

Lavi, R., Tal, M., \& Dori, Y. J. (2021). Perceptions of STEM alumni and students on developing 21st century skills through methods of teaching and learning, Studies in Educational Evaluation, 70, 101002. DOI:10.1016/j.stueduc.2021.101002.

Marinescu, C., Cicea, C., \& Colesca, S. E. (2019). Tracking biofuels-innovation relationship through scientific and technological advances, Management Research and Practice, 11 (2), 31-44.

McLaughlin, M. (1995). Employability skills profile: What are employers looking for? (Report No. 39). Greenshoro, NC: Clearinghouse on Counseling and Student Services. (ERIC Document Reproduction Service No. ED 399484). 
Narayanan, V. K., Olk, P. M., \& Fukami, C. V. (2010). Determinants of internship effectiveness: An exploratory model. Academy of Management Learning \& Education, 9(1), 61-80.

Nghia, T. L. H., \& Duyen, N. T. M. (2018). Internship-related learning outcomes and their influential factors. Education+ training, 60(1), 69-81. DOI:10.1108/ET-02-2017-0030.

Nicolescu, L., \& Nicolescu, C. (2018). Using PLS-SEM to build an employability confidence model for higher education recipients in the field of business studies. Kybernetes, 48(9): 1965 - 1988. DOI:10.1108/K-04-2018-0165.

Pardo-Garcia, C., \& Barac, M. (2020). Promoting Employability in Higher Education: A Case Study on Boosting Entrepreneurship Skills. Sustainability, 12(10), 4004. DOI:10.3390/su12104004.

Popa, I., \& Gora, A. A. (2020), Bibliometric Analysis of the Links between Knowledge Management and Competitive Advantage, publicat în The Best Romanian Management Studies 2017-2018, Editura Trivent Publishing.

Popescu, M. E., \& Mocanu, C. (2018). Do apprenticeships increase youth employability in Romania? A propensity score matching approach. Acta Universitatis Danubius. Economica, 14(1), 215-225.

Slof, B., Nijdam, D., \& Janssen, J. (2016). Do interpersonal skills and interpersonal perceptions predict student learning in CSCL-environments?, Computers \& Education, 97, 49-60. DOI:10.1016/j.compedu.2016.02.012.

Spence, S., \& Hyams-Ssekasi, D. (2015). Developing business students' employability skills through working in partnership with a local business to deliver an undergraduate mentoring programme, Higher Education, Skills and Work-Based Learning, 5(3), 299 - 314. DOI:10.1108/HESWBL-07-2014-0034.

US. Department of Labor, The Secretary's Commission on Achieving Necessary Skills (SCANS). (1991). What work requires of schools: A SCANS report for America 2000. Washington, DC.

Yorke, M. (2006). Employability in Higher Education: What It Is, What It Is Not. York: The Higher Education Academy, 1.

Van Eck, N. J., \& Waltman, L. (2007). VOS: A new method for visualizing similarities between objects, in Advances in data analysis: Proceedings of the 30th annual conference of the German Classification Society, ed. J. Lenz \& R. Decker (Heidelberg: Springer, 2007), 299-306.

Van Eck, N. J., \& Waltman, L. (2010). Software survey: VOSviewer, a computer program for bibliometric mapping, Scientometrics 84(2): 523-538, doi: 10.1007/s11192-009-0146-3.

Van Eck, N. J., \& Waltman, L. (2011). 'Text mining and visualization using VOSviewer,' ISSI Newsletter, 7(3), 50-54.

Van Eck, N. J., \& Waltman, L. (2021) VOSviewer software version 1.6.17, developed at Leiden University's Centre for Science and Technology Studies (CWTS), 2021. Available at https://www.vosviewer.com/

Waltman, L., Van Eck, N. J., \& Noyons, E. C. M. (2010). A unified approach to mapping and clustering of bibliometric networks, Journal of Informetrics, 4(4), 629-635, doi:10.1016/j.joi.2010.07.002. 